Proceedings of the 12th International Symposium on Physics of Materials, Prague, September 4-8, 2011

\title{
Anelastic Phenomena in Mg-Al Alloys
}

\author{
D. NAgArajan ${ }^{a}$, C.H. CACEReS ${ }^{a, *}$ AND J.R. GRIfFiths ${ }^{b}$ \\ ${ }^{a}$ ARC-Centre of Excellence for Design in Light Metals, Materials Engineering, School of Engineering \\ The University of Queensland, Brisbane, QLD 4072, Australia \\ ${ }^{b}$ CSIRO Process Science \& Engineering, P.O. Box 883, Kenmore, QLD 4069, Australia
}

\begin{abstract}
Cyclic loading-unloading in tension and compression has been used to quantify the anelastic behaviour, in the form of hysteresis loops, of pure $\mathrm{Mg}$ and three $\mathrm{Mg}-\mathrm{Al}$ alloys $(0.5,2$, and 9 at.\% $\mathrm{Al})$. The effect reached a maximum at a plastic strain of $\approx 0.02$ for all of the materials, and decreased at higher strains. The amount of anelasticity at any given strain was smaller for the dilute alloys in comparison with the pure $\mathrm{Mg}$ whereas it increased above that of pure $\mathrm{Mg}$ for the most concentrated alloy. Possible reasons for this behaviour are discussed in terms of reversible twinning, solid solution softening, and hardening and short range order.
\end{abstract}

PACS: 62.40. $+\mathrm{i}, 61.72 . \mathrm{Mm}, 81.40 . \mathrm{Cd}, 75.40 .-\mathrm{s}$

\section{Introduction}

The stress/strain curves of many hexagonal close-packed metals and alloys exhibit large hysteresis loops in cyclic loading/unloading tests, the effect having been reported in alloy AZ91 [1], Mg-Zn solid solutions [2], and zirconium [3]. A common feature of the plastic deformation mechanisms of these metals is the simultaneous operation of slip and twinning, the twinning being necessary to help satisfy the von Mises criterion of five independent slip systems for homogeneous plastic deformation. Twins may be unstable in the deformed state [4], partly reverting once the stress is removed [5] or reversed $[6,7]$. In situ neutron diffraction studies $[5,6]$ on pure $\mathrm{Mg}$ and on a $\mathrm{Mg}-8.5$ wt\% $\mathrm{Al}$ alloy showed that partial reversion of $\{1012\}$ twins is the main cause for the hysteresis loops. In situ SEM studies on a $\mathrm{Mg}-\mathrm{Al}$ alloy [8] confirmed these observations as well as noting that new $\{10 \overline{1} 2\}$ twins may form upon unloading, adding to the overall anelastic effect.

There have been no studies of the influence of solute content on the anelasticity in $\mathrm{Mg}-\mathrm{Al}$ alloys, especially at low strains and low alloy levels. A systematic examination of the effect of solute concentration on the magnitude of the anelastic effect thus appeared warranted, and was the object of this work. Al contents were selected to cover the range of dilute and concentrated solid solutions.

\section{Experimental procedure}

Pure $\mathrm{Mg}$ and $\mathrm{Mg}-\mathrm{Al}$ alloys with aluminium contents of $0.5,2$, and 9 at.\% were used for the study. The required compositions were achieved by adding predetermined amounts of aluminium to molten commercially pure magnesium. For the pure metal the grains were refined by adding appropriate amounts of a $\mathrm{Mg}-22.5$

\footnotetext{
* corresponding author; e-mail: c.caceres@uq.edu.au
}

mass\% Zr master alloy. No grain refiner was used for the alloys. Plates of dimensions $175 \times 150 \times 33 \mathrm{~mm}^{3}$ were produced by sand-casting. The chemical compositions of the alloys, determined by inductively coupled plasma atomic emission spectrometry, are given in Table.

TABLE

The chemical compositions and the grain sizes of the alloys.

\begin{tabular}{c|c|c|c}
\hline \hline $\begin{array}{c}\text { Alloy } \\
\text { nomenclature }\end{array}$ & $\begin{array}{c}\mathrm{Al} \\
\text { [at.\%] }\end{array}$ & $\begin{array}{c}\mathrm{Zr} \\
\text { [at.\%] }\end{array}$ & $\begin{array}{c}\text { grain size } \\
{[\mu \mathrm{m}]}\end{array}$ \\
\hline $\mathrm{Mg}$ & nil & 0.20 & 170 \\
$0.5 \% \mathrm{Al}$ & 0.45 & nil & 660 \\
$2 \% \mathrm{Al}$ & 2.03 & nil & 230 \\
$9 \% \mathrm{Al}$ & 9.03 & nil & 130
\end{tabular}

The plates were sectioned into $15 \times 9 \times 85 \mathrm{~mm}^{3}$ bars which were solution heat treated at $413^{\circ} \mathrm{C}$ for $10 \mathrm{~h}$ for the 0.5 and $2 \% \mathrm{Al}$ alloys, and for $20 \mathrm{~h}$ for the $9 \% \mathrm{Al}$ alloy, followed by quenching into water. The pure $\mathrm{Mg}$ bars were stress relieved at $250{ }^{\circ} \mathrm{C}$ for $2 \mathrm{~h}$ followed by furnace cooling. Samples for grain size measurement were polished by standard methods and etched using a mixture of $20 \mathrm{ml}$ acetic acid, $3 \mathrm{~g}$ picric acid, $20 \mathrm{ml} \mathrm{H}_{2} \mathrm{O}$, and $50 \mathrm{ml}$ ethanol. The grain sizes, also listed in Table, were measured by the linear intercept method. At least 2000 boundary intercepts were counted for each material.

Flat tensile specimens with a cross-section of $5 \times 6 \mathrm{~mm}^{2}$ and a gauge length of $25 \mathrm{~mm}$, and cylindrical compression specimens $20 \mathrm{~mm}$ in diameter and $40 \mathrm{~mm}$ in height were machined from the heat treated bars. The specimens were loaded and unloaded cyclically with increasing strain values. A pair of opposing knife-edge extensometers was used to average out any errors caused by minor misalignments. The tensile specimens were tested to fracture, whereas in compression the testing was stopped at a strain of 0.07 . 


\section{Observations}

Figure 1 illustrates the tensile loading-unloading hysteresis loops in a pure $\mathrm{Mg}$ specimen and defines the experimental parameters.

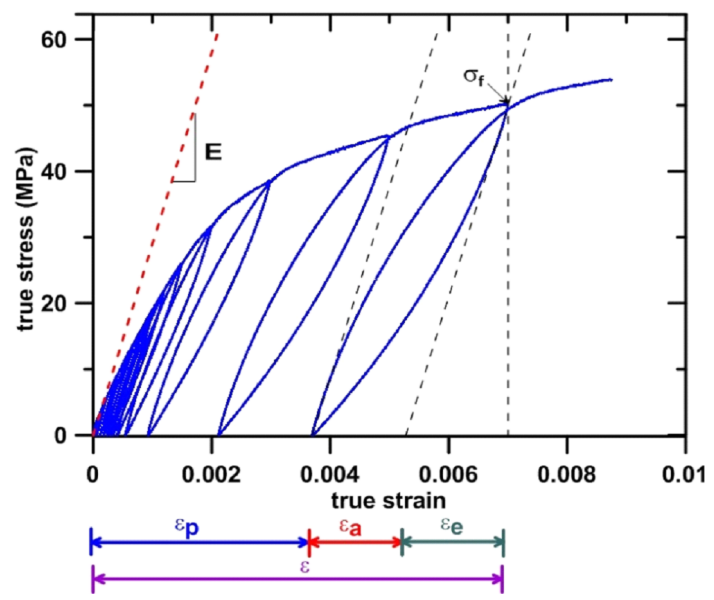

Fig. 1. Tensile loading-unloading hysteresis loops of a pure $\mathrm{Mg}$ specimen. $E$ is the elastic modulus, $\sigma_{\mathrm{f}}$ is the flow stress at the start of the unloading, $\varepsilon$ is the total strain at stress $\sigma_{\mathrm{f}} ; \varepsilon_{\mathrm{p}}$ is the true plastic strain, $\varepsilon_{\mathrm{a}}$ and $\varepsilon_{\mathrm{e}}$ are the anelastic and linear elastic strains, respectively.

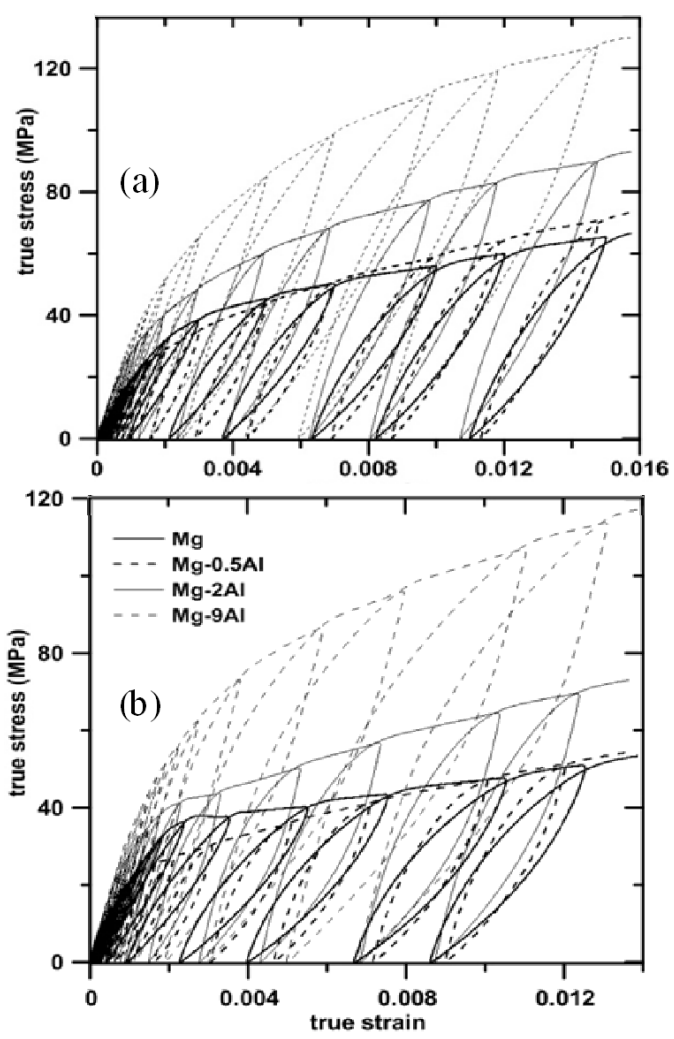

Fig. 2. Loading-unloading loops: (a) tension testing; (b) compression testing.

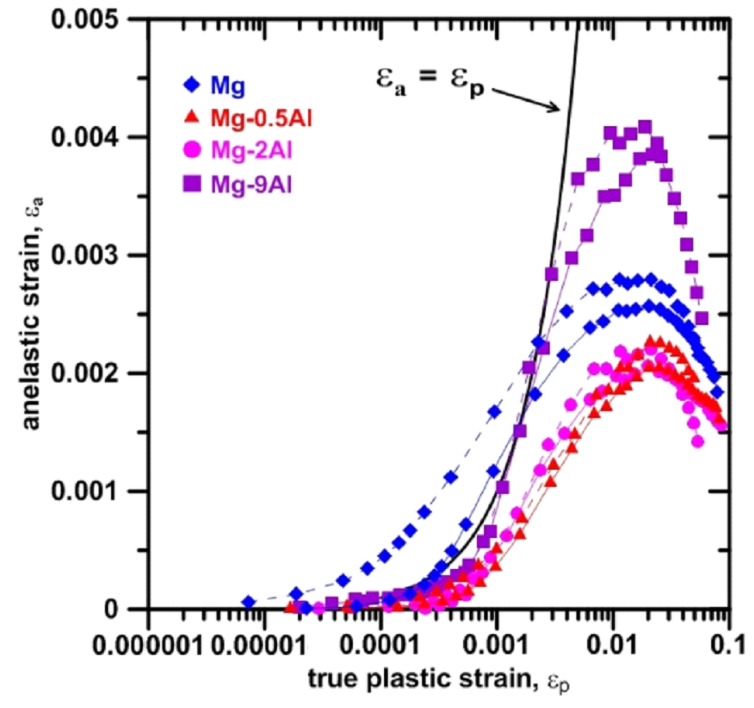

Fig. 3. The anelastic strain, $\varepsilon_{\mathrm{a}}$, as a function of true plastic strain, $\varepsilon_{\mathrm{p}}$, in tension (solid lines) and compression (dashed lines) for the materials studied. The line at which $\varepsilon_{\mathrm{a}}=\varepsilon_{\mathrm{p}}$ is drawn as a reference.

Cyclic flow curves for tension and compression loading are shown in Fig. 2a and $\mathrm{b}$ and the anelastic strain is plotted as a function of true plastic strain in Fig. 3. In pure $\mathrm{Mg}$ the anelasticity progressively developed after a true plastic strain of about $10^{-4}$ and about $10^{-5}$ in tension and compression respectively, reaching a maximum of about 0.0025 at a plastic strain of $\approx 0.02$. The addition of solute delayed the development of the anelastic strain to a plastic strain of about $3 \times 10^{-4}$, reaching a maximum at the same strain as for the pure $\mathrm{Mg}$. The anelastic effect was smaller for both the 0.5 and $2 \% \mathrm{Al}$ alloys than for either the pure $\mathrm{Mg}$ or the $9 \%$ alloy. Anelasticity in the $9 \%$ alloy was less than for pure $\mathrm{Mg}$ at low strains but exceeded it at larger strains.

\section{Discussion}

Previous work has shown that the anelastic strain varies with grain size, $d$, solute content, $c$, plastic strain, $\varepsilon_{\mathrm{p}}$, and on whether loading is tensile or compressive. The present results show that anelasticity is smaller for the two intermediate alloys than for either the pure $\mathrm{Mg}$ or the more concentrated alloy. This is in contrast to $\mathrm{Mg}-\mathrm{Zn}$ alloys in which anelasticity decreases monotonically with Zn content [2] (see also Sect. 4.4). Secondly, anelasticity in the two intermediate alloys is almost the same despite the difference in solute content and the difference in grain size. Since it is clear that anelasticity in $\mathrm{Mg}$ alloys as a whole is caused by reversible twinning, the results are discussed in the light of that understanding.

\subsection{Tension/compression asymmetry}

The loops were wider, and the anelastic effect larger, in compression than in tension for all of the materials. This result is not new, matching that from other studies $[1,2,6,8]$. As discussed in Refs. [2, 9] this asymmetry 
is consistent with the hypothesis that the anelasticity is attributable to reversed twinning since the asymmetry matches the polar nature of twinning. The present results add weight to that interpretation.

\subsection{Comparison between pure $M g$ and the $M g-9 \%$ alloy}

The grain sizes for these two sets of specimens were similar, so the major effects are those of solute content and plastic strain. At very small plastic strains the anelastic effect is greater for pure $\mathrm{Mg}$ but for strains greater than $\approx 0.002$ the anelastic effect is greater for the alloy. The major effect of $\mathrm{Al}$ at this high concentration of $9 \%$ is to produce solid solution hardening on the slip planes whereas it has little hardening effect for twinning (see Sect. 4.4) and, therefore, the net effect is to increase the relative propensity for twinning. This effect dominates at strains greater than $\approx 0.002$ but not at lower strains; the details of the physics involved are unclear at this stage.

\subsection{The $0.5 \%$ and $2 \%$ alloys}

The major observation is that the anelasticity of these alloys is less than for either the pure $\mathrm{Mg}$ or the $9 \%$ alloy. This minimum with solute content is in contrast to $\mathrm{Mg}-\mathrm{Zn}$ alloys in which anelasticity decreased steadily with solute content [2]. The decreased anelastic effect can only stem from a decrease in twin activity, with the $0.5 \%$ and $2 \%$ alloys having fewer twins at a given strain than either the pure $\mathrm{Mg}$ or the $9 \%$ alloy. Such a decrease in twinning can be rationalised as follows: substitutional solutes, including $\mathrm{Al}$ and $\mathrm{Zn}$, cause solid solution softening for prism slip in magnesium [10]. When this happens, twinning becomes less necessary as a deformation mechanism and the amount of twinning decreases at a given strain $[1,2]$. It is, therefore, speculated that the amount of twinning decreases with solute as long as solid solution softening either continues to increase with the solute concentration or at least stays constant. Softening of the prism planes has, in fact, only been confirmed for $\mathrm{Al}$ contents of up to $0.5 \%$ (higher solute levels were not investigated in [10]) and our work suggests that this should be done to define the transition between solid solution softening and hardening. This explanation is complicated by the fact that the grain size of the $0.5 \%$ alloy is almost three times larger than that of the $2 \%$ alloy. If the solute effect discussed above were the same in both alloys this large grain size should have resulted in a decreased anelasticity in the $2 \% \mathrm{Al}$ alloy. That this has not happened suggests that the solute softening is more pronounced for $2 \% \mathrm{Al}$ than for $0.5 \%$.

\subsection{Comparison between $\mathrm{Mg}-\mathrm{Al}$ and $\mathrm{Mg}-\mathrm{Zn}$ alloys}

It has been mentioned several times in this discussion that anelasticity in $\mathrm{Mg}-\mathrm{Zn}$ alloys, unlike for $\mathrm{Mg}-\mathrm{Al}$, decreases steadily with increasing alloy content. This difference in behaviour can be understood by noting that
$\mathrm{Mg}-\mathrm{Zn}$ solid solutions have a strong propensity to develop short range order [11] whereas Al forms near-random solid solutions [12]. Twinning in $\mathrm{Mg}$ involves atomic shuffling [13] which is indifferent to the existence of a random solid solution, but which becomes more difficult in the presence of order [14]. In the $\mathrm{Mg}-\mathrm{Al}$ alloys solid solution hardening makes dislocation plasticity (including prism slip) increasingly difficult for concentrations beyond at least $2 \%$ but it does not affect the critical resolved shear stress for twinning. In contrast, in the $\mathrm{Mg}-\mathrm{Zn}$ alloys the (short range) order acts as a strong deterrent to twinning, hence causing the monotonic decrease in anelasticity with increasing solute level.

An obvious query to the above arguments stems from noting that the maximum solid solubility of $\mathrm{Al}$ is as high as 18.6 at.\% whereas that of $\mathrm{Zn}$ is only 2.4 at.\%. The latter was the maximum concentration of $\mathrm{Zn}$ in the experiments of Ref. [2], and up to about 2 at.\% both solutes have the similar effect of reducing the anelasticity. For alloy contents greater than 2 at.\%, Al increases twinning, whereas higher concentrations of $\mathrm{Zn}$ are not accessible, and the contrasting behaviour of the two solutes looks unsubstantiated. This is so unless the respective rates of solid solution hardening are considered [2]: due to the short range order effects, a concentration of 2.4 at.\% $\mathrm{Zn}$ produces a strong hardening, affecting both dislocation slip and twinning. Aluminium in solution has rather moderate hardening effects and only upon dislocation slip.

\section{Conclusions}

The anelastic behaviour of sand-cast pure $\mathrm{Mg}$ and binary $\mathrm{Mg}-\mathrm{Al}$ alloys with solute contents of $0.5,2$, and 9 at.\% has been studied under cyclic loading in tension and compression. It is shown that in pure Mg the anelastic strain increases with the applied strain, reaching a maximum of $\approx 0.0025$ at a plastic strain of 0.02 . For the alloys, the maximum anelastic strain was 0.002 for the $0.5 \%$ and $2 \% \mathrm{Al}$ alloys and 0.004 for the $9 \% \mathrm{Al}$ alloy. This behaviour contrasts with that of $\mathrm{Mg}-\mathrm{Zn}$ alloys, for which the effect decreases monotonically with the solute concentration.

It is suggested that at low Al contents, solution softening of the prism planes reduces the need to twin, whereas at the higher concentrations solution hardening in all slip systems makes dislocation plasticity more difficult, leading to an increased amount of twinning.

The variation of anelasticity with alloy content in $\mathrm{Mg}-\mathrm{Al}$ alloys is qualitatively different from $\mathrm{Mg}-\mathrm{Zn}$ alloys. It is suggested that this stems from the tendency of $\mathrm{Mg}-\mathrm{Zn}$ alloys to develop short range order as opposed to the near-random solid solutions of $\mathrm{Mg}-\mathrm{Al}$.

\section{Acknowledgments}

We are grateful to the reviewer for helpful comments on the manuscript. 


\section{References}

[1] C.H. Cáceres, T. Sumitomo, M. Veidt, Acta Mater. 51, 6211 (2003).

[2] G.E. Mann, T. Sumitomo, C.H. Cáceres, J.R. Griffiths, Mater. Sci. Eng. 456A, 138 (2007)

[3] R.E. Reed-Hill, E.P. Dahlberg, W.A. Slippy, Jr., Trans. Metall. Soc. AIME 233, 1766 (1965).

[4] T.W. Duerig, R. Zadno, An engineer's perspective of pseudoelasticity, in: Engineering Aspects of Shape Memory Alloys, Ed. T.W. Duerig, ButterworthHeineman, 1990, p. 369.

[5] M.A. Gharghouri, G.C. Weatherly, J.D. Embury, J. Root, Philos. Mag. 79, 1671 (1999).

[6] M.A. Gharghouri, Ph.D. Thesis, McMaster University, Hamilton, Ontario 1996.

[7] R.L. Woolley, J. Inst. Met. 83, 57 (1954).
[8] Z. Keshavarz, M.R. Barnett, in: Magnesium Technology 2005, Eds. N.R. Neelameggham, H.I. Kaplan, B.R. Powell, TMS (The Minerals, Metals and Materials Society), San Francisco, CA, 2005, p. 171.

[9] S.R. Agnew, M.H. Yoo, C.N. Tomé, Acta Mater. 49, 4277 (2001).

[10] A. Akhtar, E. Teghtsoonian, Acta Metall. 17, 1351 (1969).

[11] C.H. Cáceres, A. Blake, Phys. Status Solidi A 194 147 (2002).

[12] C.H. Cáceres, D.M. Rovera, J. Light Met. 1/3, 151 (2001).

[13] G.W. Groves, A. Kelly, P. Kidd, Crystallography and Crystal Defects, Wiley, West Sussex 2000, Ch. 10.

[14] J.W. Cahn, Acta Metall. 25, 1021 (1977). 